immediately concerned with mental health, there is a move to change to greater compulsion. The coroner in the Beverley Lewis case heard in 1989, in which a mentally handicapped adult died from her schizophrenic mother's neglect, criticised those who had not applied for guardianship, and said that the mother should have been required to take medication. The Law Commission presently sitting is considering inter alia "consent to certain kinds of medication provided the patient does not actively object" but continues to advise against the imposition of treatment forcibly in the community. Thus a stage is being placed between the present guardianship order and the forcible administration of treatment to a resisting patient in the community. Where a patient objects to treatment in a community setting, but does not actively resist it, and when treatment can be given safely, it is being urged that this should no longer be unlawful.

\section{Conclusions}

Guardianship may now be applied to patients formerly thought to require prolonged stay in hospital, particularly the schizophrenic patient with poor prognosis. As the numbers under guardianship remain low, few psychiatrists can have had experience of more than one or two such orders. Objections to the use of guardianship are thus largely theoretical and usually rest on the reluctance of the local social services department and the belief that the powers involved are weak, and exclude compulsory treat- ment. The secret of success lies in good cooperation between the psychiatrist and the social services department, and in using the order as a means to a comprehensive plan of community management. To do this requires the local authority to have sufficient resources to monitor, support and educate the patient. In this situation guardianship can then be used to command local authority resources. Our patient, RP, was an example of a recalcitrant and very deluded patient, previously failing to respond to mental health care, but faced with a united and determined team approach, the relatively weak powers of guardianship could be used to their limit, to ensure successful community treatment. It is possible that legislation will extend these powers in the future.

\section{References}

Barnes, M., Bowle, R. \& Fisher, M. (1990) Sectioned: Social Services and the 1983 Mental Health Act. pp. 96-101. Routledge.

FENNEL, P. (1992) Balancing care and control: guardianship, community treatment orders and patient safeguards. International Journal of Law and Society, 15, 205-235.

Grant, W. (1992) Guardianship Orders - a review of their use under the 1983 Mental Health Act. Medicine, Science and the Law, 32, 319-324.

Wattis, J. P., Grant, W., Traynor, J. \& Harris, S. (1990) Use of guardianship under the 1983 Mental Health Act. Medicine, Science and the Law, 30, 313-316.

A full list of references is available on request to Dr Symonds.

\title{
Psychiatrists able to assist patients who cannot speak English
}

The College receives regular enquiries from members of the College and general practitioners regarding patients who are unable to speak English. We are asked if we can give the name of a psychiatrist able to communicate with patients in their own language.

We maintain a list of members who are fluent in languages other than English. This list is also forwarded to the central offices of the Mental Health Act Commission.
At present, we are having particular difficulty in identifying members who speak Chinese, Gujarati, Bengali, Sudanese, Arabic, Farsi, Somalian and Swahili. I should be grateful if any member who is able and willing to help in this way could write to me giving the relevant particulars, (language spoken, contact address and telephone number) so that this list can be expanded.

VANESSA Cameron The Secretary 